\title{
Aspectos florísticos e fitossociológicos de um trecho de Floresta Estacional Perenifólia na Fazenda Trairão, Bacia do rio das Pacas, Querência-MT
}

\author{
Sustanis Horn KUNZ¹, Natália Macedo IVANAUSKAS², Sebastião Venâncio MARTINS³, Elias SILVA4 , Daniel \\ STEFANELLO 5
}

\begin{abstract}
RESUMO
A borda sul da região amazônica apresenta um tipo peculiar de floresta, denominada de Floresta Estacional Perenifólia, que atualmente vem sofrendo severos impactos ambientais devido à expansão da fronteira agrícola no Norte do Estado de Mato Grosso. Diante da falta de estudos neste tipo florestal, objetivou-se identificar a composição florística e a estrutura fitossociológica do componente arbóreo de um trecho florestal na Fazenda Trairão em Querência-MT. A amostragem da vegetação consistiu na distribuição de 200 pontos-quadrantes, sendo considerados os quatro indivíduos mais próximos de cada ponto que tivessem DAP (diâmetro à altura do peito) igual ou superior a $10 \mathrm{~cm}$. A densidade total foi de 728 ind./ha, distribuídos em 49 espécies, 39 gêneros e 24 famílias. A família que apresentou maior riqueza foi Fabaceae (cinco espécies), seguida por Burseraceae e Euphorbiaceae, cada uma com quatro espécies, consideradas também as mais ricas em trechos de Floresta Amazônica. As espécies de maior Valor de Importância (VI) foram Ocotea leucoxylon (Sw.) Laness., Xylopia amazonica R.E. Fr., Myrcia multiflora (Lam.) DC., Chaetocarpus echinocarpus (Baill.) Ducke e Protium pilosissimum Engl., mas não tiveram a mesma representatividade em outros trechos de Floresta Estacional Perenifólia, evidenciando diferenças estruturais desta unidade fitogeográfica. A comunidade avaliada possui porte fino, pois a maioria dos indivíduos concentra-se nas classes de diâmetro entre 10 e 14,9 cm e altura entre 10,6 e 16,5 m. O índice de Shannon $(3,17)$ é considerado baixo por se tratar de floresta amazônica, na qual a diversidade é superior a 4,0.
\end{abstract}

PALAVRAS-CHAVES: Amazônia, florística, fitossociologia, Floresta Estacional Perenifólia, Mato Grosso.

\section{Floristic and phytosociological aspects of a Seasonal Evergreen Forest area in the Trairão Farm, rio das Pacas Basin, Querência-MT}

\begin{abstract}
The southern border of the Amazon region presents a peculiar type of forest called Seasonal Evergreen Forest, which has currently undergone several environmental impacts due to the agriculture frontier expansion from the Northern state of Mato Grosso. Due to the lack of studies on this type of forest, the objective of this study was to identify the floristic composition and phytosociological structure of the arborous component from a forest area in the Trairão Farm, Querência - MT, Brazil. The vegetation sampling was composed of the distribution of 200 quadrant-points in which the four individuals closest to each point, with DAP (diameter to height breast) equal or superior to $10 \mathrm{~cm}$ were considered. The total density of the sampled area was 728 ind./ha distributed into 49 species, 39 genera and 24 families. The species presenting the highest richness was Fabaceae (five species), followed by Burseraceae and Euphorbiaceae, with four species each, and considered as the richest in some Amazon forest areas. The species of highest Importance Value (IV) were Ocotea leucoxylon (Sw.) Laness., Xylopia amazonica R.E. Fr. and Myrcia multiflora (Lam.) DC., Chaetocarpus echinocarpus (Baill.) Ducke and Protium pilosissimum Engl., but did not present the same representativity as in other Seasonal Evergreen Forest area, evidencing structural differences within this phytogeographic unit. The majority of individuals from this community present slender size, with diameter ranging from 10 to $14.9 \mathrm{~cm}$ and height from 10.6 to $16.5 \mathrm{~m}$. The Shannon index (3.17) may be considered as low in relation to the Amazon Forest in which the diversity is above 4.0 .
\end{abstract}

KEYWORDS: Amazon region, floristic, phytosociology, Seasonal Evergreen Forest, Mato Grosso.

\footnotetext{
1 Universidade Federal de Viçosa. Universidade Federal de Viçosa, Centro de Ciências Agrárias, Departamento de Engenharia Florestal. CEP 36570-000 - Viçosa - MG - Brasil. Telefone: (31) 38992466 Fax: (31) 3899 2478. e-mail: sustanishk@yahoo.com.br

2 Instituto Florestal do Estado de São Paulo. e-mail: nivanaus@yahoo.com.br

3 Universidade Federal de Viçosa. e-mail: venancio@ufv.br

${ }^{4}$ Universidade Federal de Viçosa. e-mail: eshamir@ufv.br

${ }^{5}$ Universidade Federal de Viçosa. e-mail: d_stefanello@yahoo.com.br
} 


\section{INTRODUÇÃo}

O estado do Mato Grosso possui vários domínios vegetais, destacando-se o Cerrado, o Pantanal e a Floresta Amazônica, sendo que esta última está presente mais ao Norte do Estado, mas, existem zonas de contato e/ou zonas de transição entre Cerrado e floresta.

A Secretaria de Estado de Planejamento e Coordenação Geral de Mato Grosso (SEPLAN-MT) realizou em 1999 o Zoneamento Sócio-Econômico-Ecológico com o intuito de determinar o processo de ocupação humana e o uso sustentável dos recursos naturais no Estado. Com base nesse zoneamento, a área onde está inserida a Bacia Hidrográfica do rio das Pacas, foi denominada de "Floresta Associada ao Planalto dos Parecis", sendo descrita como uma vegetação ecotonal, onde as espécies florestais umbrófilas e estacionais se misturam aleatoriamente, sem estarem associadas a um determinado tipo de clima, solo e/ou relevo (SEPLAN, 1999). Ainda em 1999, o Bioma Amazônico foi dividido em ecorregiōes conforme proposta feita por Ferreira et al. (1999), que classificaram essa mesma vegetação ecotonal em "ecorregião das florestas secas do Mato Grosso", classificação esta que também se sobrepõe uma outra definida por Veloso et al. (1991) como área de tensão ecológica. Vê-se, portanto, a dificuldade para compreender as denominaçóes sugeridas para a borda sul-amazônica. Ainda neste contexto, o termo "ecorregiáo" refere-se a um conjunto de comunidades naturais que se assemelham em termos de composição de espécies e processos ecológicos em condiçôes ambientais muitas vezes críticas para a permanência das interaçōes ecológicas (Dinerstein et al., 1995).

A Bacia do rio das Pacas situa-se na borda sul-amazônica, em acelerado processo de desmatamento para expansão das atividades agrícolas e pecuárias, que devem ser executadas de acordo com o Licenciamento Ambiental proposto pelo Estado de Mato Grosso (SEMA, 2007). A instrução normativa $n^{\circ}$ 05 de 24 de novembro de 2006 dispõe que os processos de licenciamento ambiental das propriedades rurais no Estado de Mato Grosso devem conter análise da tipologia vegetal de acordo com os mapas de vegetação do Zoneamento proposto pela SEPLAN-MT (Capítulo III, Artigo 18). Contudo, ainda se faz necessário o detalhamento do mapa da vegetação do Estado de Mato Grosso, uma vez que para o licenciamento ambiental em propriedades rurais é necessária uma escala cartográfica de maior detalhe (1:100.000/1:50.000, conforme o tamanho das áreas).

Neste sentido, este estudo visa contribuir para o detalhamento do mapa de vegetação proposto pela SEPLANMT, por meio da identificação da composição florística e da estrutura fitossociológica do componente arbóreo de um trecho de Floresta Estacional Perenifólia na Fazenda Trairão, em Querência-MT, tornando o processo de Licenciamento
Ambiental para as atividades agropecuárias na Bacia Hidrográfica do rio das Pacas mais eficiente e rápido em relação ao tema vegetação.

\section{MATERIAL E MÉTODOS}

Este estudo foi realizado na Fazenda Trairão, localizada na Bacia do rio das Pacas (Figura 1), que é uma sub-bacia hidrográfica do Alto Rio Xingu. A bacia do Pacas está situada na mesorregião Nordeste Mato-grossense e microrregião Canarana, abrangendo a porção norte do Município de Querência, a aproximadamente $700 \mathrm{~km}$ ao norte da capital Cuiabá. Apresenta aproximadamente 250 mil hectares e ainda encontra-se relativamente bem preservada. Suas nascentes que se apresentam bem conservadas, ocorrem tanto no interior quanto fora do Parque Indígena do Xingu. A área de estudo está localizada nas coordenadas geográficas 12019'20"S e 052 ${ }^{\circ} 3^{\prime 2} 29^{\prime \prime} \mathrm{O}$ (Figura 1). O clima da região é classificado como Tropical de Savana (Aw) segundo Köppen (1948), havendo duas estaçôes bem definidas: a chuvosa, que ocorre no período de outubro a abril; e a seca, que corresponde aos meses de maio a setembro (SEPLAN, 1999). O relevo é basicamente plano e os solos na área amostrada são classificados como Latossolo Amarelo e Vermelho-Amarelo (A. N. Rossete, comunicação pessoal). Para este estudo foi selecionado um trecho de Floresta Estacional Perenifólia, cuja área e seu entorno foram alvos da extração madeireira até a década de 1980, conforme relato do proprietário da Fazenda Trairão. Após esta década tal atividade foi cessada, mas visualmente ainda pode-se perceber os sinais da extração de madeira.

O método de amostragem utilizado foi o de pontoquadrantes (Cottam \& Curtis, 1956; Durigan, 2003). A partir

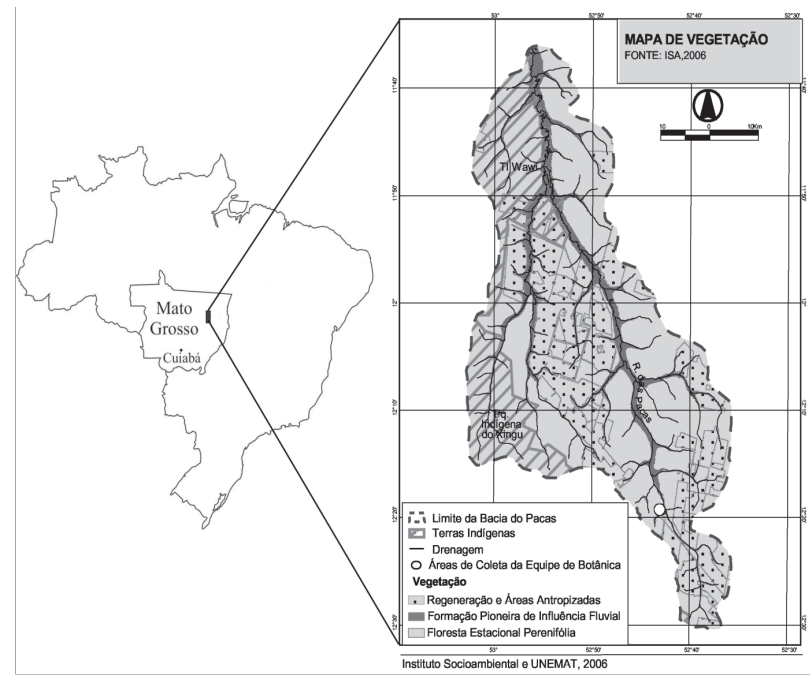

Figura 1 - Localização da Bacia Hidrográfica do rio das Pacas, com destaque para a Fazenda Trairão, município de Querência-MT. 
de $50 \mathrm{~m}$ da estrada principal da propriedade em direção ao interior da floresta, foram estabelecidas duas linhas paralelas distantes $100 \mathrm{~m}$, nas quais foram distribuídos 100 pontos a cada $15 \mathrm{~m}$, totalizando 200 pontos. Em cada ponto foram amostrados quatro indivíduos arbóreos que apresentavam diâmetro à altura de $1,30 \mathrm{~m}$ do solo (DAP) maior ou igual a $10 \mathrm{~cm}$.

Os indivíduos mortos em pé foram incluídos na amostragem, mas excluídos da análise fitossociológica, já que é uma ferramenta utilizada para analisar a estrutura da comunidade de acordo com cada espécie presente na mesma e a categoria (mortos) é representada por indivíduos de várias espécies. A identificação do material botânico foi feita em campo e, quando necessário, por comparação com exsicatas existentes em herbários, pelo uso de bibliografia especializada ou, ainda, por consulta à especialistas. A identificação seguiu o sistema de classificação da APG II (2003) e os nomes científicos foram conferidos mediante consulta no site do Missouri Botanical Garden (MOBOT, 2007). Após a identificação, o material botânico foi incorporado no herbário da Coleção Zoobotânica James Alexander Ratter do Campus Universitário de Nova Xavantina/UNEMAT (Herbário NX). A fitossociologia da área foi analisada a partir dos parâmetros fitossociológicos: Densidade, Frequêencia, Dominância e Valor de Importância (Mueller-Dombois \& Ellenberg, 1974; Durigan 2003). Foram analisadas também a Diversidade e Equabilidade das espécies na área. A análise dos dados foi realizada pelo programa FITOPAC 1 (Shepherd, 1995).

Um histograma de freqüência dos indivíduos distribuídos em classes diâmetro foi elaborado para toda a comunidade, além de serem analisadas as distribuiçôes diamétricas das cinco espécies de maior Valor de Importância. Foi adotado um intervalo de classe de $5 \mathrm{~cm}$.

\section{RESULTADOS E DISCUSSÃO}

\section{ASPECTOS FLORÍSTICOS}

No trecho de Floresta Estacional Perenifólia em QuerênciaMT foram amostradas 49 espécies. Por ser região amazônica, este valor está bem abaixo do esperado, já que estudos sobre a riqueza florística registrada em cada hectare de trechos de Floresta Ombrófila Amazônicas indicam valores entre 90 e 322 espécies (Maciel e Lisboa, 1989; Lima-Filho et al., 2001). Em um estudo realizado no Maranhão, em apenas $5.000 \mathrm{~m}^{2}$ de Floresta Ombrófila foram amostradas 88 espécies (Muniz et al.,1994b).

O número de espécies pode variar de acordo com o trecho da Floresta Amazônica inventariado, pois à medida que se afasta da regiáo central, onde predomina a Floresta Ombrófila, em direção aos extremos, a riqueza florística diminui, mas ainda continua em níveis mais altos quando comparadas com outros tipos florestais. Geralmente, na Amazônia Central são amostradas mais de 200 espécies em um hectare (Silva et al., 1992; Oliveira \& Mori, 1999; Lima-Filho et al., 2001; Oliveira \& Amaral, 2004), enquanto que mais para o Leste do Estado do Amazonas este número cai para 145 espécies (Amaral $e t$ al., 2000). Contudo, a baixa riqueza da Floresta Estacional Perenifólia na borda sul-amazônica já havia sido constatada em outros estudos em Gaúcha do Norte-MT, variando entre 51 e 66 espécies (Ivanauskas et al., 2004a).

Mori et al. (1989) explicam que a variação na quantidade de espécies na Floresta Amazônica é diferente devido às variações de solo e relevo. Estes autores argumentam que o solo pode agir como um fator limitante, tornando um local mais pobre em espécies do que em outro, onde não há limitação alguma. Acrescentam também que a riqueza pode ser explicada em função do relevo, sendo que em regiôes onde o relevo é suave há uma baixa riqueza de espécies, pois as oportunidades de especialização de nicho são diminuídas. Talvez estes fatores possam explicar, em parte, a baixa quantidade de espécies observadas nos trechos de relevo praticamente plano onde ocorre a Floresta Estacional Perenifólia. No entanto, tal premissa só poderá ser confirmada através de novos estudos que relacionem fatores ambientais e vegetação.

As 49 espécies estão distribuídas em 39 gêneros e 24 famílias (Tabela 1). Apesar de todas as espécies terem sido identificadas, geralmente as listagens da flora amazônica ficam incompletas devido à dificuldade em identificar as espécies florestais, pois muitas famílias são complexas taxonomicamente e faltam especialistas na flora regional (Ivanauskas et al., 2004b).

O total de $64 \%$ das famílias e $79,48 \%$ dos gêneros foi representado por apenas uma espécie. Os gêneros mais diversificados foram Miconia e Ocotea, que apresentaram três espécies cada (Tabela 1).

A abundância de indivíduos nem sempre é proporcional ao número de espécies, ou seja, poucas espécies podem ser representadas por grandes populaçôes ou uma única espécie pode ser muito abundante na comunidade. Esta observação também se estende às famílias, que podem apresentar alta riqueza, mas serem pouco abundantes. Em um trecho de Floresta Ombrófila Densa amazônica, por exemplo, a família Caesalpiniaceae foi representada por 12 espécies e 56 indivíduos, enquanto Lecythidaceae apresentou apenas cinco espécies e 101 indivíduos, evidenciando a desproporção entre riqueza e abundância para as famílias (Amaral et al., 2000).

No presente estudo, a família Fabaceae foi a mais representativa em termos de riqueza, detendo $16 \%$ (8) do total de espécies. Contudo, estas espécies estão distribuídas em apenas 18 indivíduos, enquanto Lauraceae, mesmo sendo a mais abundante (137 indivíduos), foi representada por apenas três espécies. Burseraceae e Euphorbiaceae ocuparam a $2^{\circ}$ 
Tabela 1 - Relação das famílias e espécies encontradas em um trecho de Floresta Estacional Perenifólia na Fazenda Trairão, Querência, Mato Grosso. $\mathrm{NC}=$ Número do Coletor.

\begin{tabular}{|c|c|c|}
\hline Famílias/Espécies & Nome Popular & NC \\
\hline \multicolumn{3}{|l|}{ ANNONACEAE } \\
\hline Guatteria schomburgkiana Mart. & cabo-de-rodo & DS-78 \\
\hline Xylopia amazonica R.E. Fr. & envira-vassourinha & DS-48 \\
\hline Xylopia frutescens Aubl. & envira-folha-peluda & DS-167 \\
\hline \multicolumn{3}{|l|}{ APOCYNACEAE } \\
\hline Aspidosperma discolor A. DC. & carapanauba & DS-79 \\
\hline $\begin{array}{l}\text { Himatanthus sucuuba (Spruce ex } \\
\text { Müll. Arg.) Woodson }\end{array}$ & sucuúba & DS-168 \\
\hline \multicolumn{3}{|l|}{ ARALIACEAE } \\
\hline $\begin{array}{l}\text { Schefflera morototoni (Aubl.) } \\
\text { Maguire, Steyerm. \& Frodin }\end{array}$ & morototó & DS-221 \\
\hline \multicolumn{3}{|l|}{ BIGNONIACEAE } \\
\hline Jacaranda copaia (Aubl.) D. Don & pará-pará & DS-89 \\
\hline \multicolumn{3}{|l|}{ BURSERACEAE } \\
\hline Protium pilosissimum Engl. & breu-peludo & DS-220 \\
\hline Protium unifoliolatum Engl. & breu-aroeira & DS-90 \\
\hline Trattinnickia glaziovii Swart & $\begin{array}{l}\text { breu-sucuruba- } \\
\text { folha-grande }\end{array}$ & DS-45 \\
\hline Trattinnickia rhoifolia Willd. & $\begin{array}{l}\text { breu-sucuruba- } \\
\text { branco }\end{array}$ & DS-60 \\
\hline \multicolumn{3}{|l|}{ CHRYSOBALANACEAE } \\
\hline Hirtella racemosa Lam. & cariperana & DS-61, 112 \\
\hline Licania blackii Prance & cariperana & DS-146 \\
\hline Licania sothersiae Prance & cariperana & DS-50 \\
\hline \multicolumn{3}{|l|}{ COMBRETACEAE } \\
\hline Buchenavia capitata (Vahl) Eichler & mirindiba, cuiarana & DS-164 \\
\hline \multicolumn{3}{|l|}{ CONNARACEAE } \\
\hline Connarus perrottetii (DC.) Planch. & conaro & DS-52 \\
\hline \multicolumn{3}{|l|}{ ELAEOCARPACEAE } \\
\hline Sloanea eichleri K. Schum. & $\begin{array}{l}\text { urucurana-folha- } \\
\text { grande }\end{array}$ & DS-66 \\
\hline \multicolumn{3}{|l|}{ EUPHORBIACEAE } \\
\hline Alchornea schomburgkii Klotzsch & -------- & DS-126 \\
\hline $\begin{array}{l}\text { Chaetocarpus echinocarpus } \\
\text { (Baill.) Ducke }\end{array}$ & -------- & DS-68 \\
\hline Maprounea guianensis Aubl. & caxicha & DS-165 \\
\hline Pera coccinea (Benth.) Müll. Arg. & café-bravo & DS-101 \\
\hline \multicolumn{3}{|l|}{ FABACEAE } \\
\hline $\begin{array}{l}\text { Apuleia leiocarpa (Vogel) J.F. } \\
\text { Macbr. }\end{array}$ & garapia & DS-141 \\
\hline
\end{tabular}

Tabela 1 - Continuação

\begin{tabular}{|c|c|c|}
\hline Famílias/Espécies & Nome Popular & NC \\
\hline Copaifera langsdorffii Desf. & pau-de-óleo & DS-169 \\
\hline $\begin{array}{l}\text { Diplotropis purpurea (Rich.) } \\
\text { Amshoff }\end{array}$ & sucupira-preta & DS-182 \\
\hline Diplotropis triloba Gleason & sucupira-preta & DS-191 \\
\hline $\begin{array}{l}\text { Enterolobium schomburgkii } \\
\text { (Benth.) Benth. }\end{array}$ & fava-orelha & DS-139 \\
\hline Hymenaea courbaril L. & jatobá & DS-91 \\
\hline Inga heterophylla (Sw.) Willd. & inga-pretinho & DS-96 \\
\hline Ormosia paraensis Ducke & tento & DS-55 \\
\hline \multicolumn{3}{|l|}{ HUMIRIACEAE } \\
\hline Sacoglottis guianensis Benth. & uxirana & DS-47 \\
\hline \multicolumn{3}{|l|}{ LAURACEAE } \\
\hline Ocotea guianensis Aubl. & louro-prata & DS-217 \\
\hline Ocotea leucoxylon (Sw.) Laness. & louro-abacate & DS-54 \\
\hline Ocotea caudata (Nees) Mez & louro-preto & DS-71 \\
\hline \multicolumn{3}{|l|}{ MELASTOMATACEAE } \\
\hline Miconia cuspidata Mart. ex Naudin & ------- & DS-129 \\
\hline $\begin{array}{l}\text { Miconia punctata (Desr.) D. Don } \\
\text { ex DC. }\end{array}$ & tinteiro-vermelho & DS-57 \\
\hline Miconia pyrifolia Naudin & tinteiro-branco & DS-45 \\
\hline Mouriri apiranga Spruce ex Triana & murici & DS-196 \\
\hline
\end{tabular}

\section{MELIACEAE}

\begin{tabular}{|c|c|c|}
\hline Trichilia micrantha Benth. & ------- & DS-190 \\
\hline \multicolumn{3}{|l|}{ MENISPERMACEAE } \\
\hline Abuta grandifolia (Mart.) Sandwith & ------- & DS-88 \\
\hline \multicolumn{3}{|l|}{ MYRISTICACEAE } \\
\hline Virola sebifera Aubl. & ucuúba-de-sangue & DS-41 \\
\hline \multicolumn{3}{|l|}{ MYRTACEAE } \\
\hline Myrcia multiflora (Lam.) DC. & murta & DS-65 \\
\hline \multicolumn{3}{|l|}{ OCHNACEAE } \\
\hline Ouratea discophora Ducke & pau-de-cobra & DS-77 \\
\hline \multicolumn{3}{|l|}{ OLACACEAE } \\
\hline Minquartia guianensis Aubl. & ------- & DS-218 \\
\hline \multicolumn{3}{|l|}{ RUBIACEAE } \\
\hline Amaioua guianensis Aubl. & canela-de-veado & DS-51 \\
\hline \multicolumn{3}{|l|}{ SAPOTACEAE } \\
\hline $\begin{array}{l}\text { Micropholis egensis (A. DC.) } \\
\text { Pierre }\end{array}$ & mangabazinho & DS-91 \\
\hline
\end{tabular}


Tabela 1 - Continuação

\begin{tabular}{|c|c|c|}
\hline Famílias/Espécies & Nome Popular & NC \\
\hline $\begin{array}{l}\text { Pouteria gardneri (Mart. \& Miq.) } \\
\text { Baehni }\end{array}$ & abiu & DS-67 \\
\hline Pouteria torta (Mart.) Radlk. & abiurana & DS-81 \\
\hline \multicolumn{3}{|l|}{ SIMAROUBACEAE } \\
\hline Simarouba amara Aubl. & pau-de-caixão & DS-104 \\
\hline \multicolumn{3}{|l|}{ VOCHYSIACEAE } \\
\hline Vochysia ferruginea Mart. & quaruba-cedro & DS-70, 148 \\
\hline
\end{tabular}

posição em termos de riqueza (4 espécies), mas em relação à densidade ocuparam a $4^{\circ}$ (62 indivíduos) e $5^{\circ}$ (49 indivíduos) posição, respectivamente.

Em um estudo realizado em Floresta Ombrófila Densa na Amazônia Central, Oliveira e Amaral (2004) relatam que apenas seis famílias contribuíram com $45 \%$ da riqueza total, evidenciando que a alta porcentagem de espécies está concentrada em poucas famílias botânicas. Confirmando esta premissa, no trecho amostrado em Querência-MT cerca de $30 \%$ do total de espécies da comunidade estão distribuídas apenas entre as famílias Fabaceae (8 espécies), Burseraceae (4) e Euphorbiaceae (4).

A família Burseraceae tem alta representatividade na Floresta Ombrófila Amazônica, sendo registrada como uma das mais ricas em espécies (Silva et al., 1986; Mori et al., 1989; Matos e Amaral, 1999; Lima-Filho et al., 2001; Oliveira \& Amaral, 2004), mas em trechos de Floresta Estacional Perenifólia esta família não esteve entre as mais ricas (Ivanauskas et al., 2004b). Já Euphorbiaceae apresentou alta riqueza florística (12 a 17 espécies) tanto na Floresta Estacional Perenifólia em Gaúcha do Norte-MT (Ivanauskas et al., 2004b), como em trechos de Floresta Ombrófila Densa próximo a Manaus-AM (Oliveira e Amaral, 2004) e em Oriximiná-PA (Lima-Filho et al., 2004), mas em estudos realizados em Florestas Ombrófilas em Rondônia e no Amapá foi representada respectivamente por três e uma espécies (Maciel \& Lisboa, 1989; Mori et al., 1989).

Fabaceae possui um dos maiores valores de riqueza (11 a 24 espécies) em áreas de Floresta Ombrófila Densa (Mori et al., 1989; Amaral et al., 2000; Lima-Filho et al., 2004; Oliveira \& Amaral, 2004). Contudo, na Floresta Estacional Perenifólia em Gaúcha do Norte-MT esta família foi representada por apenas seis espécies (Ivanauskas et al., 2004b).

O índice de Shannon ( $\mathrm{H}^{\prime}$ ) foi 3,17 e a eqüabilidade de Pielou (J') foi 0,81. Almeida et al. (1993) observaram que a diversidade das comunidades arbóreas está diretamente relacionada com a quantidade de espécies raras, ou seja, a alta porcentagem de espécies raras contribui significativamente para o aumento da diversidade local. Desta forma, esta observação pode explicar, em parte, o baixo valor de diversidade encontrado. Enquanto nas áreas de Floresta Ombrófila da região amazônica já foram registrados valores de diversidade acima de 4,0 (Muniz et al., 1994a; Oliveira \& Amaral, 2004), nos trechos de Floresta Estacional Perenifólia a diversidade não ultrapassa o valor de 3,3 (Ivanauskas et al., 2004a), considerando o mesmo critério de inclusão do presente estudo (DAP $\geq 10 \mathrm{~cm}$ ). Apesar da baixa diversidade, a eqüabilidade sugere que o trecho analisado apresenta baixa dominância ecológica.

\section{ASPECTOS FITOSSOCIOLÓGICOS}

A densidade total na área amostrada foi de 728 indivíduos por hectare e a área basal total, considerando os indivíduos mortos, foi $24,77 \mathrm{~m}^{2} / \mathrm{ha}$. A porcentagem de indivíduos mortos amostrados na comunidade foi de 11,37\% (91 indivíduos), valor que pode ser considerado alto. Em um trecho de Floresta Ombrófila em Maranhão apenas cinco indivíduos mortos foram amostrados, apesar do tamanho da amostra ter sido de apenas 0,5 hectare (Muniz et al., 1994b).

Os resultados referentes à densidade e área basal são superiores àqueles encontrados para os trechos de Floresta Estacional Perenifólia, que variaram entre 515 e 588 ind./ha e 18,63 e $23,95 \mathrm{~m}^{2} / \mathrm{ha}$, respectivamente (Ivanauskas et al., 2004a). Contudo, a densidade do presente estudo está na média daquela relatada para a Floresta Ombrófila Amazônica, que geralmente está em torno de 700 indivíduos por hectare (Silva et al., 1992; Oliveira \& Mori, 1999; Amaral et al., 2000; Lima-Filho et al., 2001), podendo existir trechos contendo 393 ind./ha em Altamira-PA (Campbell et al., 1986) ou máximo de 862 ind./ha, como é o caso do trecho de Floresta Ombrófila Densa da Bacia do rio Juruá-AM (Silva et al., 1992).

Para a Floresta Ombrófila, a menor área basal registrada é de $27 \mathrm{~m}^{2} /$ ha (Silva et al., 1986; Silva et al., 1992), mas pode atingir até $40 \mathrm{~m}^{2} / \mathrm{ha}$ (Salomão et al., 1988). No entanto, as comparações relacionadas à área basal devem ser analisadas com cautela, pois os valores encontrados são diretamente influenciados pelo diâmetro mínimo escolhido para a amostragem. Outro fator preponderante é o tipo florestal e o estado de conservação que se encontra o trecho analisado. No caso do trecho na Fazenda Trairão, o baixo valor da área basal pode ser devido à extração seletiva de madeira que ocorreu na área anos atrás, permanecendo apenas os indivíduos de menor porte.

As dez espécies de maior valor de importância (VI) corresponderam a $64,35 \%$ do VI total, havendo alta representatividade de poucas espécies na comunidade. As que se destacaram foram: Ocotea leucoxylon, Xylopia amazonica, Myrcia multiflora, Chaetocarpus echinocarpus e Protium pilosissimum (Tabela 2). 
Tabela 2 - Parâmetros fitossociológicos das espécies arbóreas amostradas no levantamento fitossociológico realizado na Fazenda Trairão, Querência-MT. $\mathrm{NI}$ - Número de indivíduos, DR - Densidade relativa (\%), DoR - Dominância relativa (\%), FR - Freqüência relativa (\%),VC -Valor de Cobertura, VI - Valor de importância.

\begin{tabular}{|c|c|c|c|c|c|c|}
\hline Espécies & $\mathrm{NI}$ & $\mathrm{DR}$ & DoR & $\mathrm{FR}$ & VC & $\mathrm{Vl}$ \\
\hline Ocotea leucoxylon & 92 & 12,98 & 22,03 & 12,19 & 35,01 & 47,19 \\
\hline Xylopia amazonica & 89 & 12,55 & 10,12 & 10,94 & 22,67 & 33,61 \\
\hline Myrcia multiflora & 66 & 9,31 & 4,99 & 9,69 & 14,30 & 23,99 \\
\hline $\begin{array}{l}\text { Chaetocarpus } \\
\text { echinocarpus }\end{array}$ & 45 & 6,35 & 3,88 & 6,25 & 10,22 & 16,47 \\
\hline $\begin{array}{l}\text { Protium } \\
\text { pilosissimum }\end{array}$ & 47 & 6,63 & 2,73 & 5,78 & 9,36 & 15,14 \\
\hline $\begin{array}{l}\text { Connarus } \\
\text { perrottetii }\end{array}$ & 34 & 4,80 & 3,27 & 5,00 & 8,06 & 13,06 \\
\hline $\begin{array}{l}\text { Vochysia } \\
\text { vismiifolia }\end{array}$ & 20 & 2,82 & 6,97 & 2,97 & 9,79 & 12,76 \\
\hline Abuta grandifolia & 33 & 4,65 & 1,71 & 5,00 & 6,37 & 11,37 \\
\hline Ocotea caudata & 26 & 3,67 & 2,71 & 3,59 & 6,38 & 9,97 \\
\hline $\begin{array}{l}\text { Sacoglottis } \\
\text { guianensis }\end{array}$ & 19 & 2,68 & 4,00 & 2,81 & 6,68 & 9,49 \\
\hline Ocotea guianensis & 19 & 2,68 & 3,45 & 2,50 & 6,13 & 8,63 \\
\hline Hirtella racemosa & 18 & 2,54 & 2,93 & 2,81 & 5,47 & 8,28 \\
\hline $\begin{array}{l}\text { Amaioua } \\
\text { guianensis }\end{array}$ & 21 & 2,96 & 1,15 & 2,97 & 4,11 & 7,08 \\
\hline Sloanea eichleri & 17 & 2,40 & 1,58 & 2,50 & 3,98 & 6,48 \\
\hline $\begin{array}{l}\text { Guatteria } \\
\text { schomburgkiana }\end{array}$ & 15 & 2,12 & 1,55 & 2,34 & 3,67 & 6,01 \\
\hline Pouteria gardneri & 10 & 1,41 & 2,76 & 1,56 & 4,17 & 5,74 \\
\hline Trichilia micrantha & 15 & 2,12 & 0,76 & 2,19 & 2,88 & 5,06 \\
\hline Licania blackii & 9 & 1,27 & 2,04 & 1,41 & 3,31 & 4,72 \\
\hline Miconia pyrifolia & 12 & 1,69 & 0,88 & 1,88 & 2,57 & 4,44 \\
\hline Miconia punctata & 12 & 1,69 & 0,60 & 1,56 & 2,29 & 3,85 \\
\hline $\begin{array}{l}\text { Aspidosperma } \\
\text { discolor }\end{array}$ & 5 & 0,71 & 2,28 & 0,78 & 2,99 & 3,77 \\
\hline $\begin{array}{l}\text { Protium } \\
\text { unifoliolatum }\end{array}$ & 10 & 1,41 & 0,52 & 1,56 & 1,93 & 3,49 \\
\hline $\begin{array}{l}\text { Diplotropis } \\
\text { purpurea }\end{array}$ & 4 & 0,56 & 2,22 & 0,63 & 2,79 & 3,41 \\
\hline $\begin{array}{l}\text { Ouratea } \\
\text { discophora }\end{array}$ & 7 & 0,99 & 0,80 & 1,09 & 1,79 & 2,88 \\
\hline Ormosia paraensis & 6 & 0,85 & 0,96 & 0,94 & 1,81 & 2,75 \\
\hline $\begin{array}{l}\text { Himatanthus } \\
\text { sucuuba }\end{array}$ & 5 & 0,71 & 1,16 & 0,78 & 1,87 & 2,65 \\
\hline Apuleia leiocarpa & 1 & 0,14 & 2,13 & 0,16 & 2,27 & 2,42 \\
\hline Pouteria torta & 4 & 0,56 & 1,06 & 0,63 & 1,62 & 2,25 \\
\hline
\end{tabular}

Tabela 2 - Continuação

\begin{tabular}{|c|c|c|c|c|c|c|}
\hline Espécies & $\mathrm{NI}$ & $\mathrm{DR}$ & DoR & FR & VC & $\mathrm{Vl}$ \\
\hline Jacaranda copaia & 1 & 0,14 & 1,71 & 0,16 & 1,85 & 2,00 \\
\hline $\begin{array}{l}\text { Minquartia } \\
\text { guianensis }\end{array}$ & 4 & 0,56 & 0,76 & 0,63 & 1,32 & 1,95 \\
\hline Virola sebifera & 5 & 0,71 & 0,36 & 0,78 & 1,06 & 1,85 \\
\hline $\begin{array}{l}\text { Buchenavia } \\
\text { capitata }\end{array}$ & 2 & 0,28 & 1,25 & 0,31 & 1,53 & 1,84 \\
\hline $\begin{array}{l}\text { Trattinnickia } \\
\text { rhoifolia }\end{array}$ & 3 & 0,42 & 0,70 & 0,47 & 1,12 & 1,59 \\
\hline $\begin{array}{l}\text { Copaifera } \\
\text { langsdorffii }\end{array}$ & 2 & 0,28 & 0,94 & 0,31 & 1,22 & 1,53 \\
\hline Mouriri apiranga & 4 & 0,56 & 0,20 & 0,63 & 0,77 & 1,39 \\
\hline Simarouba amara & 3 & 0,42 & 0,42 & 0,47 & 0,84 & 1,31 \\
\hline Licania sothersiae & 3 & 0,42 & 0,27 & 0,47 & 0,70 & 1,16 \\
\hline $\begin{array}{l}\text { Micropholis } \\
\text { egensis }\end{array}$ & 3 & 0,42 & 0,21 & 0,47 & 0,63 & 1,10 \\
\hline Miconia cuspidata & 3 & 0,42 & 0,21 & 0,47 & 0,63 & 1,10 \\
\hline $\begin{array}{l}\text { Schefflera } \\
\text { morototoni }\end{array}$ & 2 & 0,28 & 0,35 & 0,31 & 0,64 & 0,95 \\
\hline Alchornea sp. & 2 & 0,28 & 0,25 & 0,31 & 0,54 & 0,85 \\
\hline $\begin{array}{l}\text { Trattinnickia } \\
\text { glaziovii }\end{array}$ & 2 & 0,28 & 0,13 & 0,31 & 0,42 & 0,73 \\
\hline Xylopia frutescens & 2 & 0,28 & 0,10 & 0,31 & 0,38 & 0,69 \\
\hline $\begin{array}{l}\text { Enterolobium } \\
\text { schomburgkii }\end{array}$ & 2 & 0,28 & 0,10 & 0,31 & 0,38 & 0,69 \\
\hline Diplotropis triloba & 1 & 0,14 & 0,30 & 0,16 & 0,44 & 0,59 \\
\hline $\begin{array}{l}\text { Hymenaea } \\
\text { courbaril }\end{array}$ & 1 & 0,14 & 0,19 & 0,16 & 0,33 & 0,49 \\
\hline $\begin{array}{l}\text { Maprounea } \\
\text { guianensis }\end{array}$ & 1 & 0,14 & 0,18 & 0,16 & 0,32 & 0,48 \\
\hline Inga heterophylla & 1 & 0,14 & 0,09 & 0,16 & 0,23 & 0,39 \\
\hline Pera coccinea & 1 & 0,14 & 0,04 & 0,16 & 0,18 & 0,34 \\
\hline Total & 709 & 100 & 100 & 100 & 200 & 300 \\
\hline
\end{tabular}

A espécie Ocotea leucoxylon se destacou neste índice devido à alta dominância apresentada (Tabela 2), sendo o dobro da dominância registrada para Xylopia amazonica. Apesar disso, estas duas espécies não possuem densidades muito diferentes, pois Ocotea leucoxylon foi representada por 92 indivíduos e Xylopia amazonica teve uma densidade total de 89 indivíduos (Tabela 2). Esta discrepância em relação à dominância pode ser explicada pelo fato desta espécie conter indivíduos com até $50 \mathrm{~cm}$ de diâmetro, enquanto as outras cinco espécies de maior VI atingem no máximo $35 \mathrm{~cm}$. 
Para Vochysia vismiifolia há uma relação inversa entre densidade e dominância, pois foi representada por menos indivíduos que Abuta grandifolia e, mesmo assim, destacou-se em valor de importância devido o elevado diâmetro das árvores (Tabela 2). Já Myrcia multiflora apresentou baixos valores de dominância, contudo ocupou a $3^{\circ}$ posição em função da elevada densidade e freqüência relativa (Tabela 2). A distinção observada em relação à densidade e dominância entre estas espécies deve-se principalmente ao fato de ocuparem diferentes estratos na floresta: Ocotea leucoxylon, Xylopia amazonica e Vochysia vismiifolia apresentam maiores valores de dominância, pois ocorrem no dossel da floresta. Em contrapartida, as outras espécies, que são mais representativas em densidade, aparecem comumente no sub-dossel e sub-bosque.

A estrutura sociológica de uma determinada fitofisionomia pode assumir valores diferentes de acordo com os aspectos geográficos e fatores ambientais do local. Contudo, geralmente as espécies em uma mesma fitofisionomia e em regiōes próximas tendem a seguir um mesmo padrão, pois algumas espécies tendem a ser muito freqüentes em diferentes trechos ou podem assumir altos valores de importância em tal fitofisionomia.

Em áreas de cerrado sensu stricto, por exemplo, Qualea parviflora Mart. e Curatella americana L. são comumente registradas como espécies que apresentam altos valores de importância (Furley et al., 1988; Nascimento \& Saddi 1992; Marimon et al., 1998; Nogueira et al., 2001), sendo consideradas características de ambientes de cerrado sensu stricto, além de evidenciarem a ampla distribuição geográfica nesta fitofisionomia. Mabea fistulifera Mart., Xylopia sericea A. St.-Hil. e Piptadenia gonoacantha (Mart.) J.F. Macbr. são frequentemente encontradas em trechos de Floresta Estacional Semidecidual na região de Viçosa-MG (Mariscal Flores, 1993; Rezende, 1995; Fernandes, 1998; Almeida Júnior, 1999; Silva et al., 2004). Já para a região amazônica, as espécies Eschweilera coriacea (DC.) S.A. Mori e Protium apiculatum Swart se destacam em valor de importância em diferentes trechos de Floresta Ombrófila (Matos \& Amaral, 1999; Amaral et al., 2000; Lima-Filho et al., 2001; Oliveira \& Amaral, 2004). Diante disso, pode-se dizer que existem espécies que se tornam marcantes nas fitofisionomias, havendo um padrão de distribuição horizontal para certas espécies.

Para a Floresta Estacional Perenifólia do Alto Rio Xingu, as espécies Ocotea leucoxylon, Xylopia amazonica e Chaetocarpus echinocarpus sempre apresentam alto valor de importância nos trechos avaliados nas sub-bacias do Pacuneiro (Ivanauskas et al. 2004a) e, do rio das Pacas. No entanto, Myrcia multiflora, Vochysia vismiifolia, Abuta grandifolia, Ocotea caudata e Sacoglottis guianensis, estão entre as dez mais importantes na comunidade da Trairão, mas não foram registradas na bacia do rio Pacuneiro, a qual também pertence à Bacia do Alto Xingu.
Já as espécies Miconia pyrifolia e Amaoiua guianensis que se destacaram em VI nos trechos de interflúvio do Pacuneiro tiveram pouca representatividade na Fazenda Trairão.

O trecho analisado em Querência-MT apresentou nove espécies raras (apenas um indivíduo por hectare) ou 14,28\% do total de espécies (Tabela 2). Apuleia leiocarpa, representada por apenas um indivíduo, teve maior dominância que Abuta grandifolia, que ficou em $8^{\circ}$ posição em VI (Tabela 2), justificando as distinçôes entre os estratos, pois Apuleia leiocarpa é uma espécie típica de dossel e Abuta grandifolia ocorre no sub-dossel. É interessante ressaltar que Apuleia leiocarpa, Diplotropis triloba e Hymenaea courbaril possuem alto potencial econômico e, por isso, são intensamente exploradas pelas madeireiras e laminadoras da região de Querência-MT. Embora possam ser naturalmente encontradas em baixas densidades, a inclusão na categoria de espécies raras ressalta que a continuidade da exploração madeireira sem plano de manejo pode ocasionar o desaparecimento destas espécies na Fazenda Trairão e no seu entorno. Em Gaúcha do Norte, Apuleia leiocarpa foi representada por oito indivíduos, os quais estavam distribuídos no interflúvio e, principalmente, na área inundável, onde atingiu maiores valores em VI (Ivanauskas et al., 2004a).

Em contraposição aos resultados obtidos no presente estudo, Muniz et al. (1994b) e Ivanauskas et al. (2004a) relatam que as florestas do domínio amazônico são representadas por poucas espécies abundantes e muitas espécies raras. De fato, as espécies raras podem representar desde 37\% (Campbell et al., 1986) até $68,05 \%$ do total de espécies, como é o caso do trecho de floresta amostrado em Caxiuanã-PA (Almeida et al., 1993). Contudo, estes autores relatam que os fatores ambientais, taxonômicos e até mesmo evolutivos interferem na abundância e raridade de algumas espécies, mesmo em áreas não muito distantes. A ocorrência da Floresta Estacional Perenifólia em um ambiente físico aparentemente homogêneo, que apresenta estacionalidade climática e relevo praticamente plano, pode estar facilitando a permanência de espécies de

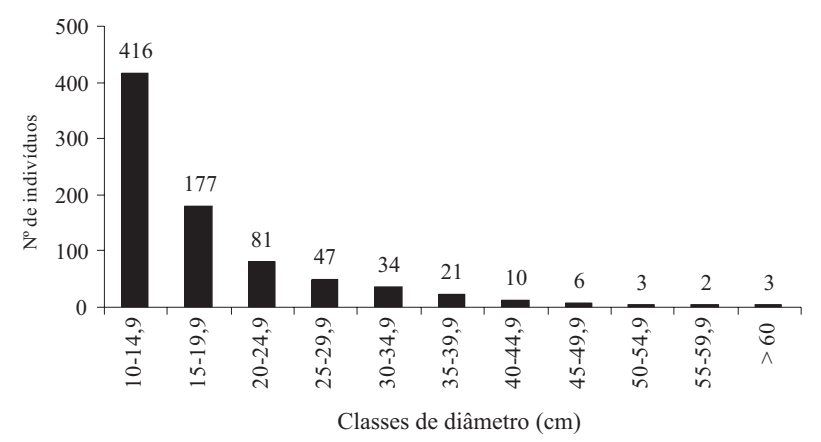

Figura 2 - Distribuição dos indivíduos por classe de diâmetro em um trecho de Floresta Estacional Perenifólia na Fazenda Trairão, Querência - MT. 


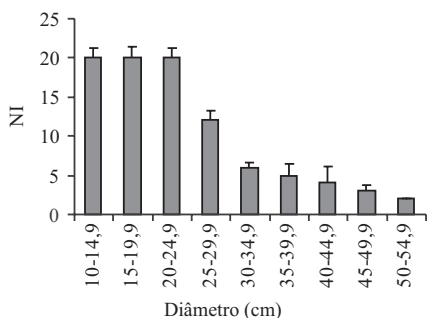

Ocotea leucoxylon

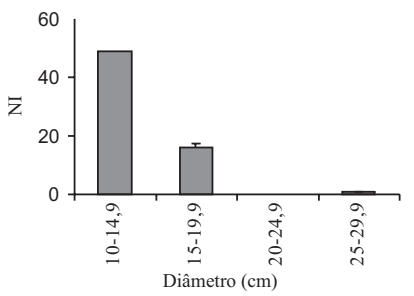

Myrcia multiflora

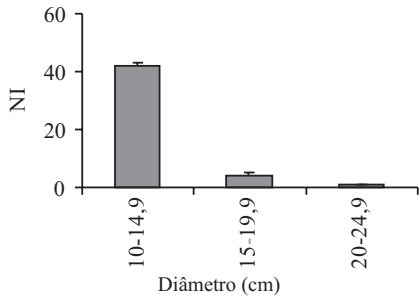

Protium pilosissimum

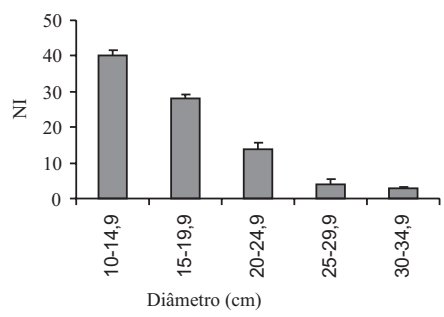

Xylopia amazonica

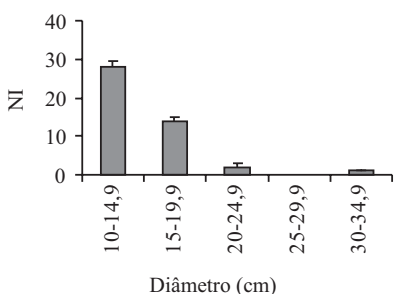

Figura 3 - Distribuição dos indivíduos por classe de diâmetro para as espécies de maior densidade em um trecho de Floresta Estacional Perenifólia na Fazenda Trairão, Querência - MT. NI - Número de Indivíduos. maior abundância e inibindo a ocorrência de espécies que ocupam nichos específicos, resultando em um ambiente com baixa riqueza florística e com poucas espécies raras (Ivanauskas et al. 2004a).

A distribuição diamétrica demonstra que 52\% de todos os indivíduos amostrados na área de estudo concentram-se na primeira classe de diâmetro, que varia de 10 a $14,99 \mathrm{~cm}$, evidenciando que os processos dinâmicos de mortalidade e crescimento estão ocorrendo na comunidade, havendo alta densidade no componente de regeneração natural (Figura 2). Contudo, é necessário avaliar se as espécies, principalmente as mais abundantes, tendem a este comportamento (Figura 3).

De acordo com a Figura 3, nota-se que apenas Xylopia amazonica mantém a distribuição em forma de J-invertido, com presença de indivíduos em todas as classes diamétricas de 10 a 34,9 cm. A maior abundância de Ocotea leucoxylon nas três primeiras classes sugere alto índice de sobrevivência na primeira fase jovem. Já Myrcia multiflora, Chaetocarpus echinocarpus e Protium pilosissimum são comumente observadas no subbosque da floresta e, por isso, seus indivíduos concentram-se mais nas primeiras classes diamétricas. Desta forma, notase que a forma de J-invertido ocorre para o povoamento total e se mantém para poucas espécies quando estudadas separadamente, mesmo em áreas que não foram exploradas.

As espécies que obtiveram os maiores diâmetros foram: Buchenavia capitata $(55,70 \mathrm{~cm})$, Aspidosperma discolor $(57,61$ $\mathrm{cm})$, Jacaranda copaia $(67,93 \mathrm{~cm})$ e Apuleia leiocarpa $(75,79$ $\mathrm{cm}$ ), embora esta última seja representada por apenas um indivíduo. Estes diâmetros máximos são inferiores quando comparados com os valores encontrados para a Floresta Ombrófila Amazônica, que apresenta árvores com até 142 $\mathrm{cm}$ de diâmetro, considerando os indivíduos com DAP $\geq 10$ cm (Silva et al., 1986). Mas de modo geral, a abundância de indivíduos nas classes diamétricas mais baixas $(10$ a $20 \mathrm{~cm}$ ) está de acordo com o padrão relatado para trechos florestais do domínio amazônico (Silva et al., 1992; Amaral et al., 2000; Ivanauskas et al., 2004a).

A comunidade florestal da Fazenda Trairão é representada por grande quantidade de espécies típicas de dossel e por poucas espécies de sub-bosque, onde $42 \%$ da densidade total concentrou-se entre 11 e $17 \mathrm{~m}$. A altura média dos indivíduos foi $16,5 \mathrm{~m}$ e as espécies que podem ser consideradas emergentes no dossel da floresta por apresentarem os maiores valores de altura são: Copaifera langsdorffi, Buchenavia capitata, Vochysia vismiifolia, Diplotropis triloba e Ormosia paraensis com altura máxima de 26 m, Diplotropis purpurea e Apuleia leiocarpa, com $27 \mathrm{~m}$, e Jacaranda copaia, que atingiu $28 \mathrm{~m}$. Em trechos de Floresta Ombrófila Amazônica, os indivíduos arbóreos podem atingir uma altura máxima de $42 \mathrm{~m}$ (Silva et al., 1986), apesar da maioria dos indivíduos se concentrarem nas classes entre 20 e 25 m (Silva et al., 1992). 
De maneira geral, o trecho analisado é representado por indivíduos de menor porte, devido aos baixos valores de diâmetro e altura encontrados. A ausência de indivíduos nas maiores classes de diâmetro, principalmente, pode ser um indício de extração de madeira, ainda mais quando se considera que espécies com alto valor econômico são encontradas na área com baixa área basal, como pode ser observado para Enterolobium schomburgkii, Hymenaea courbarile Trattinnickia glaziovii (Tabela 2). Desta forma, a ausência de indivíduos adultos aliada a fatores de perturbação, tais como extração de madeira, fragmentação ou ainda ocorrência de queimadas, pode ocasionar vários distúrbios futuramente, como por exemplo, a extinção de algumas espécies por causa da ausência de fontes de diásporos, que são essenciais à perpetuação das espécies arbóreas.

\section{CONCLUSÃO}

A baixa riqueza florística e o destaque de espécies freqüentes na área de estudo, como Ocotea leucoxylon, Xylopia amazonica e Chaetocarpus echinocarpus reforçam a inclusão da área de floresta, na Fazenda Trairão, na unidade fitogeográfica denominada Floresta Estacional Perenifólia, descrita por Ivanauskas (2002). Mesmo assim, algumas espécies predominam em determinados pontos do trecho estudado, revelando variaçôes florísticas e estruturais ao longo dessa formação.

Diferenças estruturais entre a mesma fitofisionomia são facilmente explicadas quando se considera a existência de impactos na área analisada. A extração de madeira é uma das principais causas das alterações estruturais da comunidade arbórea, proporcionando menor diversidade florística e a quase inexistência de espécies de alto valor econômico no trecho da Fazenda Trairão. Desta forma, se torna evidente que tal atividade antrópica, assim como a fragmentação que vem ocorrendo na região de Querência-MT deveriam ser melhores conduzidos para que a Floresta Estacional Perenifólia não seja, aos poucos, modificada estruturalmente pela ação humana, o que pode comprometer as funçôes ecológicas em nível de ecossistema.

\section{AGRADECIMENTOS}

Agradecemos à Agência dos Estados Unidos para Desenvolvimento Internacional (USAID), Consórcio Estradas Verdes e Fundação de Amparo à Pesquisa do Estado de Mato Grosso (FAPEMAT - Processo 08/2004) pelo apoio financeiro para o desenvolvimento do Projeto Gestão Ambiental e Ordenamento Territorial da Bacia do rio SuiáMiçu. Ao Programa Xingu/ISA (Instituto Socioambiental) e Universidade do Estado de Mato Grosso (UNEMAT) pelo apoio técnico-científico e logístico. Ao Conselho Nacional de Desenvolvimento Científico e Tecnológico (CNPq) pela concessão da bolsa de Mestrado à primeira autora. Ao proprietário da Fazenda Curumim, Sr. Cláudio Augusto Diniz e ao gerente Jean, pelo apoio para a realização deste estudo.

\section{BIBLIOGRAFIA CITADA}

Almeida Júnior, J.S. 1999. Floristica e fitossociologia de fragmentos da floresta estacional semidecidual, Viçosa, Minas Gerais. Dissertação de Mestrado, Universidade Federal de Viçosa, Viçosa, Minas Gerais. 148pp.

Almeida, S.S.; Lisboa, P.L.B; Silva, A.S.L. 1993. Diversidade florística de uma comunidade arbórea na Estação Científica "Ferreira Penna", em Caxiuanã (Pará). Boletim do Museu Paraense Emílio Goeldi, série Botânica, 9(1): 93-128.

Amaral, I.L.; Matos, F.D.; Lima, J. 2000. Composição florística e parâmetros estruturais de um hectare de floresta densa de terra firme no rio Uatumã, Amazônia, Brasil. Acta Amazonica, 30(3): 377-392.

APG II (ANGIOSPERM PHYLOGENY GROUP). 2003. An update of the Angiosperm Phylogeny Group classification for the orders and families of flowering plants: APG II. Botanical Journal of the Linnean Society, 141: 399-436.

Campbell, D.G.; Daly, D.C.; Prance, G.T.; Maciel, U.N. 1986. Quantitative ecological inventory of terra firme and várzea tropical forest on the Rio Xingu, Brazilian Amazon. Brittonia, 38(4): 369393.

Cottam, G.; Curtis, J.T. 1956. The use of distance measures in phytosociological sampling. Ecology, 37(3): 451-460.

Dinerstein, E.; Olson, D.M.; Graham, D.J.; Webster, A.; Primm, S.; Bookbinder, M.; Fornet, M.; Ledec, G. 1995. A conservation assessment of the terrestrial ecoregions of Latin America and the Caribbean. World Wildlife Fund Report to the World Bank/LATEN.

Durigan, G. 2003. Métodos para análise de vegetação arbórea. In: CullenJúnior, L.; Rudran, R.; Valladares-Padua, C. (Orgs.). Métodos de estudos em biologia da conservação e manejo da vida silvestre. UFPR, Curitiba, Paraná. p. 455-479.

Fernandes, H.A.C. 1998. Dinâmica e distribuição de espécies arbóreas em uma floresta secundária no domínio da Mata Atlântica. Dissertação de Mestrado, Universidade Federal de Viçosa, Viçosa, Minas Gerais. 148pp.

Ferreira, L.V.; Sá, R.L.; Buschbacher, R.; Batmanian, G.; Silva, J.M.C.; Arruda, M.B.; Moretti, E.; Sá, L.F.S.N.; Falcomer, J.; Bampi, M.L. 1999. Identificação de áreas prioritárias para a conservação da biodiversidade através da representatividade das unidades de conservação e tipos de vegetação nas ecorregiōes da Amazônia Brasileira. In: Avaliação e identificação de açôes prioritárias para a conservação, utilização sustentável e repartição dos benefícios da biodiversidade da Amazônia brasileira: Programa Nacional da Diversidade Biológica. Seminário de Consulta, Macapá. (http:// www.isa.org.br). Acesso em: 20/04/07.

Furley, P.A.; Ratter, J.A.; Gifford, D.R. 1988. Observations on the vegetation of eastern Mato grosso, Brazil. III. The woody vegetation and soils of the Morro da Fumaça, Torixoréu. Proceedings of the Royal Society of London, Series B, Biological Sciences, 235(1280): 259-280.

Ivanauskas, N.M. 2002. Estudo da vegetação na área de contato entre formaçōes florestais em Gaúcha do Norte-MT. Tese de Doutorado, 
Universidade Estadual de Campinas, Campinas, São Paulo. $185 \mathrm{pp}$.

Ivanauskas, N.M.; Monteiro, R.; Rodrigues, R.R. 2003. Relações florísticas entre florestas deciduais, semideciduais e perenifólias na regiāo Centro-Oeste do Brasil. In: Claudino-Sales, V. (Org.). Ecossistemas brasileiros: manejo e conservação. Expressão Gráfica e Editora, Fortaleza, Ceará. p. 313-322.

Ivanauskas, N.M.; Monteiro, R.; Rodrigues, R.R. 2004a. Estrutura de um trecho de floresta amazônica na bacia do alto rio Xingu. Acta Amazonica, 34(2): 275-299.

Ivanauskas, N.M.; Monteiro, R.; Rodrigues, R.R. 2004b. Composição florística de trechos florestais na borda sul-amazônica. Acta Amazonica, 34(3): 399-413.

Köppen, W.P. 1948. Climatologia: com um estudio de los climas de la tierra. Fondo de Cultura Economica, México. 478pp.

Lima-Filho, D.A.; Matos, F.D.A.; Amaral, I.L.; Revilla, J.; Coêlho, L.S.; Ramos, J.F.; Santos, J.L. 2001. Inventário florístico de floresta ombrófila densa de terra firme, na região do Rio Urucu-Amazonas, Brasil. Acta Amazonica, 31(4): 565-579.

Lima-Filho, D.A.; Revilla, J.; Amaral, I.L.; Matos, F.D.A.; Coêlho, L.S.; Ramos, J.F.; Silva, G.B.; Guedes, J.O. 2004. Aspectos florísticos de 13 hectares da área de Cachoeira Porteira-PA. Acta Amazonica, 34(3): 415-423.

Maciel, U.N.; Lisboa, P.L.B. 1989. Estudo florístico de 1 hectare de mata de terra firme no $\mathrm{km} 15$ da rodovia Presidente Médici - Costa Marques (RO-429), Rondônia. Boletim do Museu Paraense Emilio Goeldi, série Botânica, 5(1): 25-37.

Marimon, B.S.; Varella, R.F.; Marimon-Júnior, B. 1998. Fitossociologia de uma área de cerrado de encosta em Nova Xavantina, Mato Grosso. Boletim do Herbário Ezechias Paulo Heringer, 3: 82-101.

Mariscal Flores, E.J. 1993. Potencial produtivo e alternativas de manejo sustentável de um fragmento de mata atlântica secundária, Município de Viçosa, Minas Gerais. Dissertação de Mestrado, Universidade Federal de Viçosa, Viçosa, Minas Gerais. 165pp.

Matos, F.D.A.; Amaral, I.L. 1999. Análise ecológica de um hectare em floresta ombrófila densa de terra-firme, Estrada da Várzea, Amazonas, Brasil. Acta Amazonica, 29(3): 365-379.

MOBOT, 2007. Missouri Botanical Garden. Trópicos Search. (http:// mobot.mobot.org/W3T/Search/vast.html). Acesso: 05/02/07.

Mori, S.A.; Rabelo, B.V.; Tsou, C.; Daly, D. 1989. Composition and structure of an eastern amazonian florest at Camaipi, Amapa, Brazil. Boletim do Museu Paraense Emílio Goeldi, série Botânica, 5(1): 3-18.

Mueller-Dombois, D.; Ellemberg, H. 1974. Aims and methods vegetation ecology. Wiley, New York. 547pp.

Muniz, F.H.; César, O.; Monteiro, R. 1994a. Aspectos florísticos quantitativos e comparativos da vegetação arbórea da Reserva Florestal do Sacavém, São Luís, Maranhão (Brasil). Acta Amazonica, 24(3/4): 189-218.

Muniz, F.H.; César, O.; Monteiro, R. 1994b. Fitossociologia da vegetação arbórea da Reserva Florestal do Sacavém, São Luís, Maranhão (Brasil). Acta Amazonica, 24(3/4): 219-236.
Nascimento, M.T.; Saddi, N. 1992. Structure and floristic composition in an área of cerrado in Cuiabá-MT, Brazil. Revista Brasileira Botânica, 15(1): 47-55.

Nogueira, P.E.; Felfili, J.M.; Silva-Junior, M.C.; Delitti, W.; Sevilha, A. 2001. Composição florística e fitossociologia de um cerrado sentido restrito no município de Canarana-MT. Boletim do Herbário Ezechias Paulo Heringer, 8:28-43.

Oliveira, A.A.; Mori, S. 1999. A central Amazonian terra firme forest. I. High tree species richness on poor soils. Biodiversity and Conservation, 8: 1219-1244.

Oliveira, A.N.; Amaral, I.L. 2004. Florística e fitossociologia de uma floresta de vertente na Amazônia Central, Amazonas, Brasil. Acta Amazonica, 34(1): 21-34.

Rezende, M. L. 1995. Regeneração natural de espécies florestais nativas em sub-bosque de um povoamento de Eucalyptus grandis e de mata secundária no município de Município de Viçosa, Zona da Mata - MG. Dissertação de Mestrado, Universidade Federal de Viçosa, Viçosa, Minas Gerais. 116pp.

Salomão, R.P.; Silva, M.F.F.; Rosa, P.L.B. 1988. Inventário ecológico em Floresta Pluvial Tropical de Terra Firme, Serra Norte, Carajás, Pará. Boletim do Museu Paraense Emílio Goeldi, Série Botânica, 4(1):1-46.

SEMA, 2007. Instrução Normativa no 05 -Disciplina os procedimentos administrativos de licenciamento ambiental das propriedades rurais no Estado de Mato Grosso. (http://www.mt.gov.br/). Acesso: 28/04/07.

SEPLAN, Secretaria de Estado de Planejamento e Coordenação Geral de Mato Grosso. 1999. Dados secundários do DSEE/MT: Zoneamento -Divulga. CD-Rom. Versão 1.01.

Shepherd, G.J. 1995. FITOPAC 1: manual do usuário. Campinas, UNICAMP. 93pp.

Silva, A.S.L.; Lisboa, P.L.B.; Maciel, U.N. 1992. Diversidade florística e estrutura em floresta densa da bacia do rio Juruá-AM. Boletim do Museu Paraense Emílio Goeldi, série Botânica, 8(2): 203-258.

Silva, M.F.F.; Rosa, N.A.; Salomão, R.P. 1986. Estudos botânicos na área do Projeto Ferro Carajás. 3. Aspectos florísticos da Mata do Aeroporto de Serra Norte, Pará. Boletim do Museu Paraense Emílio Goeldi, série Botânica, 2(2): 169-187.

Silva, N.R.S.; Martins, S.V.; Meira Neto, J.A.A.; Souza, A.L. 2004. Composição florística e estrutura de uma floresta semidecidual Montana em Viçosa - MG. Revista Árvore, 28(3): 397-405.

Veloso, H.P.; Rangel Filho, A.L.R.; Lima, J.C.A. 1991. Classificação da vegetação brasileira, adaptada a um sistema universal. Rio de Janeiro, IBGE. 123pp.

Recebido em 10/09/2007

Aceito em 06/03/2008 